\title{
Comparison of ESC and ACCF/AHA Guidelines for Oral Antiplatelet Treatment in the Management of Patients with Acute Coronary Syndrome
}

\author{
Ayhan Sarıtaş, Harun Güneş \\ Department of Emergency Medicine, Düzce University School of Medicine, Düzce, Turkey
}

\begin{abstract}
Basically, acute coronary syndrome (ACS) is caused by the partial or total occlusion of coronary arteries because of platelet activation and aggregation. Hence, one of the major components of ACS treatment is the inhibition of platelet activation and aggregation. New studies performed in recent years have led to the update of guidelines for the usage of antiplatelet agents (APA) in the treatment of ACSs. This paper aims to compare the European Society of Cardiology (ESC) and American Heart Association (ACCF/AHA) guidelines, by summarizing the key points, regarding the usage of oral APA in patients admitted to emergency departments due to ACS.
\end{abstract}

Keywords: Acute coronary syndrome, recommendations, aspirin, prasugrel, ticagrelor, clopidogrel

\section{Introduction}

Basically, acute coronary syndrome (ACS) is caused by the partial or total occlusion of coronary arteries because of platelet activation and aggregation. Hence, one of the major components of ACS treatment is the inhibition of platelet activation and aggregation. Antiplatelet agents (APA) act by inhibiting the cyclooxygenase enzyme (aspirin) and $\mathrm{P} 2 \mathrm{Y}_{12}$ receptor. The main features of $\mathrm{P} 2 \mathrm{Y}_{12}$ receptor inhibitors are listed in Table 1. New studies performed in recent years have led to the update of guidelines for the usage of APA in the treatment of ACSs. This paper aims to compare the European Society of Cardiology (ESC) $(1,2)$ and American Heart Association (ACCF/AHA) guidelines $(3,4)$, by summarizing the key points, regarding the usage of oral APA in patients admitted to emergency departments due to ACS. APA strategies that should be chosen in ST-segment elevation myocardial infarction (STEMI) and non-ST-segment elevation myocardial infarction (NSTEMI)/unstable angina (UA) pectoris cases were discussed under separate headings.

\section{APA Treatment in STEMI}

European Society of Cardiology (2) and AHA (4) guidelines on this subject were updated in 2012 and 2013, respectively. Both guidelines recommend the administration of aspirin as the first step (Class I), regardless of the treatment strategy chosen (i.e., fibrinolytic or percutaneous coronary intervention). Both guidelines also agree on the imme- diate initiation of dual antiplatelet therapy (a P2 $\mathrm{Y}_{12}$ inhibitor in addition to aspirin) (Class I). Drugs and dosages vary according to the chosen treatment strategy. Thus, the recommendations have been described separately with regard to treatment strategy. An initial aspirin dose of 150-500 $\mathrm{mg}$ and clopidogrel dose of $75 \mathrm{mg} /$ day are recommended in patients for whom no reperfusion therapy is planned (2).

\section{If fibrinolytic therapy is planned}

\section{Aspirin}

ESC (Class IB)

- 150-500 mg oral loading dose (250 mg IV loading dose if oral ingestion is not possible)

- 75-100 mg/day maintenance dose

ACCF/AHA (Class IA)

- 162-325 mg oral loading dose

- 81-325 mg/day maintenance dose

\section{P2Y ${ }_{12}$ Receptor Inhibitors}

Both guidelines recommend the use of clopidogrel in patients with STEMI for whom fibrinolytic therapy is planned. However, prasugrel and ticagrelor should not be used in such patients because the use of these agents has not been studied yet as an adjunctive treatment in fibrinolysis $(2,4)$. 
Table 1. Main features of $\mathrm{P} 2 \mathrm{Y} 12$ receptor inhibitors (1)

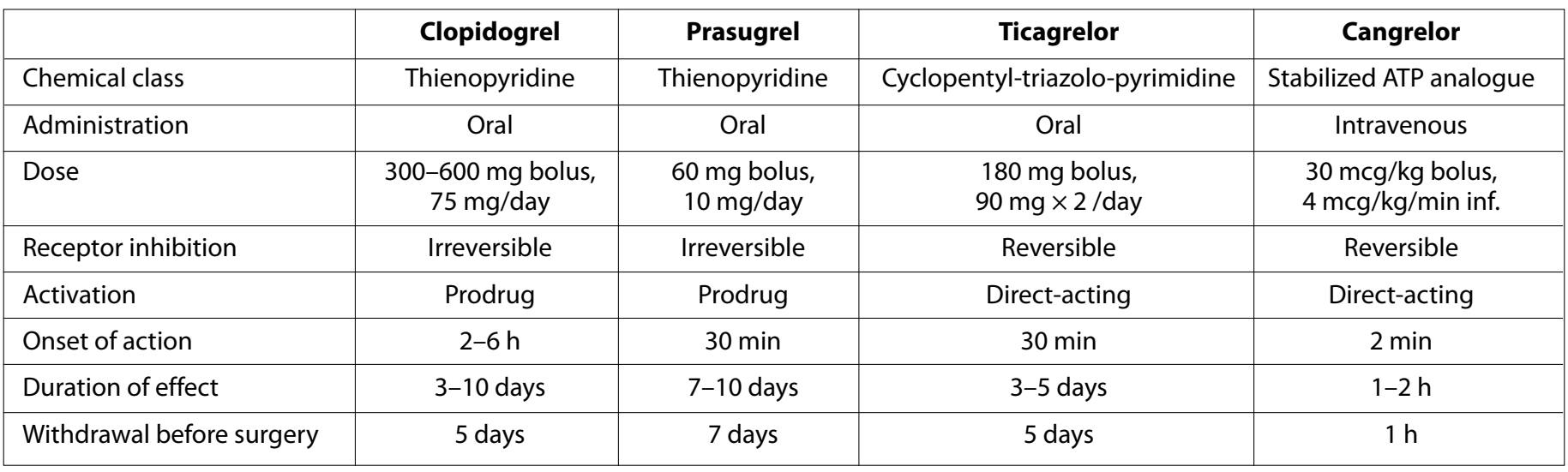

ESC and ACCF/AHA

Clopidogrel (Class IA)

- $300 \mathrm{mg}$ bolus (if age $\leq 75$ years), $75 \mathrm{mg} /$ day maintenance dose

- If the patient's age is > 75 years: $75 \mathrm{mg}$ bolus, $75 \mathrm{mg}$ / day maintenance dose

\section{If percutaneous coronary intervention is planned}

\section{Aspirin}

ESC (Class IB)

- 150-300 mg oral loading dose (80-150 mg IV loading dose if oral ingestion is not possible)

- 75-100 mg/day maintenance dose

ACCF/AHA

- $162-325 \mathrm{mg}$ bolus (Class IB)

- 81-325 mg/day maintenance (Class IA)

\section{P2Y $_{12}$ Receptor Inhibitors}

ESC

- Prasugrel (if there is no history of stroke/transient ischemic attack; age $<75$ years) (Class IB)

- Ticagrelor (Class IB)

- Clopidogrel: 600 mg bolus, 75 mg/day maintenance (if prasugrel and ticagrelor are contraindicated or not available) (Class IC)

\section{ACCF/AHA}

All the three APAs are recommended as Class IB, contrary to European guidelines.

- Clopidogrel: $600 \mathrm{mg}$ bolus, $75 \mathrm{mg} /$ day maintenance (Class IB)

- Prasugrel (Class IB)

- Ticagrelor (Class IB)

If percutaneous coronary intervention is planned in patients who have been given fibrinolytic therapy previously

ESC

Recommends the same $\mathrm{P} 2 \mathrm{Y}_{12}$ receptor inhibitor dose as it is used in patients undergoing percutaneous coronary intervention

ACCF/AHA

In patients who have not taken clopidogrel loading dose previously
- Clopidogrel: $300 \mathrm{mg}$ bolus if the patient is admitted within $24 \mathrm{~h}$ following fibrinolytic therapy (Class IC)

- Clopidogrel: $600 \mathrm{mg}$ bolus if more than $24 \mathrm{~h}$ have passed following fibrinolytic therapy (Class IC)

It is not necessary to repeat the loading dose in patients who have been given a loading dose previously.

\section{APA Treatment in UA/NSTEMI}

Aspirin therapy significantly decreases the rates of mortality and reinfarction. Aspirin is recommended in the ESC and ACCF/AHA guidelines as it has been used for patients with STEMI (Class I). Aspirin should be administered as soon as possible following patient admission, if it is not contraindicated. A clopidogrel loading dose followed by maintenance doses should be administered to patients who cannot take aspirin due to hypersensitivity or gastrointestinal intolerance (Class IB). The usage of $\mathrm{P}_{2} \mathrm{Y}_{12}$ receptor inhibitors together with aspirin provides an additive effect. Dual APA therapy is a Class IA recommendation in the ESC and ACCF/AHA guidelines.

\section{Aspirin}

ESC (Class IA)

- 150-300 mg oral loading dose

- 75-100 mg/day maintenance dose

ACCF/AHA (Class IA)

- 162-325 mg oral loading dose (75-162 mg if there is a high risk of hemorrhage)

- 81-162 mg/day maintenance dose

\section{P2Y $Y_{12}$ Receptor Inhibitors}

ESC

- Ticagrelor (Class IA)

- Prasugrel (recommended in patients proceeding to percutaneous coronary intervention) (Class IB)

- Clopidogrel (recommended in patients who cannot receive prasugrel or ticagrelor) (Class IB)

ACCF/AHA

- Ticagrelor (Class IB)

- Clopidogrel (Class IB)

- Ticagrelor in preference to clopidogrel in patients treated with an early invasive or an ischemia-guided strategy (Class IlaB) 
- Prasugrel is recommended after the patient is taken to the laboratory, and the coronary anatomy is seen if the patient was not given a $\mathrm{P}_{2} \mathrm{Y}_{12}$ receptor inhibitor until he is taken to the laboratory (Class IB)

Prasugrel is contraindicated in patients $\geq 75$ years of age or $<60$ $\mathrm{kg}$ of weight or have a history of stroke/transient ischemic attack. Besides, prasugrel should not be used in patients with an unknown coronary anatomy (Class IIIB).

Cangrelor, another $\mathrm{P}_{2} \mathrm{Y}_{12}$ receptor inhibitor, may be considered in patients who need to undergo percutaneous coronary intervention (Class IlbA). However, cangrelor is not approved by the European Medical Agency or the Federal Drug Administration. Thus, there is no specific recommendation for its usage.

\section{Conclusion}

The administration of aspirin as the first step is recommended for all patients with ACS. Since the usage of $\mathrm{P}_{2} \mathrm{Y}_{12}$ receptor inhibitors together with aspirin provides an additive effect, immediate initiation of dual antiplatelet therapy is recommended, too. A combination of an initial aspirin dose of 150-500 mg and clopidogrel dose of $75 \mathrm{mg} /$ day is recommended in STEMI patients for whom no reperfusion therapy is planned. Clopidogrel is recommended in patients with STEMI for whom fibrinolytic therapy is planned. If percutaneous coronary intervention is planned in a STEMI patient, prasugrel, and ticagrelor are preferred over clopidogrel. A clopidogrel loading dose followed by maintenance doses should be given to patients with UA/ NSTEMI who cannot take aspirin due to hypersensitivity or gastrointestinal intolerance. While choosing a $\mathrm{P}_{2} \mathrm{Y}_{12}$ receptor inhibitor for a patient with UA/NSTEMI, clopidogrel should be used only if the patient cannot take prasugrel or ticagrelor. Prasugrel should not be used in patients with a history of stroke/transient ischemic attacks or $\geq 75$ years of age or $<60 \mathrm{~kg}$ of weight. It should also be emphasized that prasugrel can only be used after the coronary anatomy is seen.

Peer-review: Externally peer-reviewed.

Conflict of Interest: No conflict of interest was declared by the authors.

Financial Disclosure: The authors declared that this study has received no financial support.

\section{References}

1. Roffi M, Patrono C, Collet JP, Mueller C, Valgimigli M, Andreotti F, et al. 2015 ESC Guidelines for the management of acute coronary syndromes in patients presenting without persistent ST-segment elevation: Task Force for the Management of Acute Coronary Syndromes in Patients Presenting without Persistent ST-Segment Elevation of the European Society of Cardiology (ESC). Eur Heart J 2016; 37: 267-315. [CrossRef]

2. Steg PG, James SK, Atar D, Badano LP, Blömstrom-Lundqvist C, Borger MA, et al. ESC Guidelines for the management of acute myocardial infarction in patients presenting with ST-segment elevation. The Task Force on the management of ST-segment elevation acute myocardial infarction of the European Society of Cardiology (ESC). Eur Heart J 2012; 33: 2569-619. [CrossRef]

3. Amsterdam EA, Wenger NK, Brindis RG, Casey DE, Ganiats TG, Holmes DR, et al. 2014 AHA/ACC guideline for the management of patients with non-ST-elevation acute coronary syndromes: a report of the American College of Cardiology/American Heart Association Task Force on Practice Guidelines. J Am Coll Cardiol 2014; 64: e139-228.

4. O'Gara PT, Kushner FG, Ascheim DD, Casey DE Jr, Chung MK, de Lemos JA, et al. 2013 ACCF/AHA guideline for the management of ST-elevation myocardial infarction: a report of the American College of Cardiology Foundation/American Heart Association Task Force on Practice Guidelines. Circulation 2013; 127: e362-425. 